\title{
Premature Ejaculation in Urban Malaysian Population: The Associations between Erectile Dysfunction(ED), Anxiety and Depression
}

\author{
Shamini Arasalingam ${ }^{a}$, Hatta Sidi ${ }^{a}, N_{g}$ Chong Guan ${ }^{b}$, Srijit Das ${ }^{c}, M^{2}$ arhani Midin ${ }^{a}$, Ramli Musa ${ }^{d}$ \\ ${ }^{a}$ Department of Psychiatry, Universiti Kebangsaan Malaysia Medical Centre (UKMMC), 56000 Cheras, Kuala \\ Lumpur, Malaysia. \\ ${ }^{b}$ Department of Psychological Medicine, Universiti Malaya Medical Centre (UMMC), 50603 Kuala Lumpur \\ Malaysia. \\ 'Department of Anatomy, Universiti Kebangsaan Malaysia Medical Centre (UKMMC), 56000 Cheras, Kuala \\ Lumpur, Malaysia. \\ ${ }^{d}$ Department of Psychiatry, Kulliyah of Medicine, International Islamic University of Malaysia (IUUM), 25200 \\ Kuantan Pahang, Malaysia.
}

\begin{abstract}
Introduction: Both premature ejaculation(PE) and erectile dysfunction(ED) are prevalent sexual health disorders that have been inadequately investigated in Malaysia, a multiethnic and conservative nation. The objective of the study was to study the relationship between PE and ED, and other common mental health issues, i.e. anxiety and depression in Malaysian urban population. Methods: The diagnosis for PE was established by clinical diagnosis using DSM-5 and ISSM definition criteria for PE, whereas a diagnosis of ED was established by the International Index of Erectile Function (IIEF) questionnaire. Anxiety and depression levels were detected from the Hospital Anxiety and Depression Scale (HADS). Results: Based on DSM-V and ISSM clinical diagnosis for PE, the prevalence of PE was found to be $25 \%$. Erectile dysfunction $(p=0.035$, OR $=3.315,95 \% \mathrm{Cl} 1.088,10.103)$ and severe anxiety $(p=0.020, \mathrm{OR}=7.656,95 \% \mathrm{Cl} 1.383,42.396)$ significantly predicted presence of PE. Conclusion: There was a strong association between PE and ED and between PE and anxiety. Routine examination for PE in male patients should address the issue and the management of both ED and anxiety among PE patients, especially in an urban Malaysian clinical and medical care setting.
\end{abstract}

Keywords: Premature ejaculation, erectile dysfunction, Urban Malaysian population, anxiety

\section{INTRODUCTION}

Studies have reported that premature ejaculation $(\mathrm{PE})$ has been one of the most common male sexual dysfunctions among men. ${ }^{1}$ Yet, there has been varying rates of reported $\mathrm{PE}$ ranging from $4 \%$ to $65 \%$ in the literature. ${ }^{1,2,3}$ Differences in the reported prevalence rate of $P E$ has been attributed to the prior lack of a standardized definition for PE as well as different methodological designs employed. Since

Corresponding author:

Professor Hatta Sidi

Department of Psychiatry

Universiti Kebangsaan Malaysia Medical Centre

(UKMMC)

56000 Cheras, Kuala Lumpur

Malaysia

Tel: 016-3112070
2013, the DSM 5 (Diagnostic and Statistical Manual's $5^{\text {th }}$ Edition) ( $^{4}$ and the ISSM (International Society for Sexual Medicine) ${ }^{1}$ has provided an evidence baseddefinition for both lifelong and acquired PE in order to help establish and standardize the diagnosis of PE.

Despite its high prevalence, PE is likely, underreported and under-treated, especially in the Asian culture like Malaysia. ${ }^{5}$ This may be attributed to the sensitive and taboo nature of sexual disclosure as well as embarrassment in seeking medical attention. ${ }^{6}$ PE results in negative repercussions on men's psychological well-being. ${ }^{7,8,9}$

The range of psychological impact includes low selfesteem, distress, shame, stress and inter-relational difficulties with their sexual partners. This range of psychological impact is diffuse and further 
delineation of these psychological symptoms need to be elucidated through validated methods.

In terms of anxiety and depression, a number of published studies had shown these as comorbid with premature ejaculation. ${ }^{10,11,12,13}$ In Malaysia, PE had been found to be associated with anxiety, depression ${ }^{14}$, Indian ethnicity and circumcision. ${ }^{15}$ Although there are well established correlates of PE in the literature, there is inadequate research in Malaysia on this topic, apart from the aforementioned two local studies. ${ }^{14,15}$ Therefore, there is a need for epidemiological data on PE in Malaysia, especially in the context of the latest evidence based definition of PE. ${ }^{1,4}$

The aim of this study was to study the relationship between the PE with other co-morbid sexual dysfunction in men and also to further assess the relationship between PE and depression and anxiety symptoms.

\section{MATERIALS \& METHODS}

\section{Ethical consideration}

This study was conducted at the Universiti Kebangsaan Malaysia Medical Centre (UKMMC) and the ethical approvals were obtained from the UKMMC Medical Ethics Committee prior to the commencement of both phases of the study (FF-443 -2014). Participants who were detected to have PE, ED and psychiatric morbidities based on the screening questionnaire were offered referral to the specialist services.

\section{Statistical analysis}

The data was analyzed using the IBM Statistical Package for Social Sciences, (SPSS) Statistics version 20 (New York, USA). The detailed relationship between the studies parameters were analyzed using appropriate statistical tests. Descriptive analysis was conducted for the baseline characteristics of clinical features. Univariate analysis was done using Chi-square analysis. Significant factor was included into multivariate logistics regression analysis. All tests were two tails with alpha (a) values of 0.05 .

The subjects were conveniently sampled from the Urology Outpatient Clinic (UOP), UKMMC. UOP UKMMC operates in two mornings every week, i.e. Monday and Friday mornings for general urology, with a patient load of 100 per clinic day. The majority of patients were male with various urological disorders, including kidney stones, urethral strictures. They run a separate Sexual Dysfunction Clinic on the third Tuesday of each month with the of 20 patients per clinic day. If the subjects agreed to participate, an informed consent was taken before they filled up the questionnaire. Subjects were given adequate privacy to fill up the questionnaire to ensure comfort and confidentiality. They returned these questionnaires back to the researcher in an envelope.

\section{Study design}

This cross-sectional study was conducted in three months duration, from June to August 2015. The inclusion criteria were: (i) males (ii) age $\geq 18$ years old; (iii) must have a female sexually active spouse; (iv) fluent in local Malay language (written \& spoken), and (v) agreeable for informed consent.

The exclusion criteria were: (i) severe mental illness (limiting engagement and informed consent); (ii) participants with severe medical illness (e.g. sepsis, kidney stones with complication, renal failure), and (iii) participants who were not in a committed heterosexual relationship.

\section{Study procedure}

Those who fulfilled the study requirement based on the inclusion and exclusion criteria of the study were recruited. Eligible subjects were then interviewed by a researcher, SA, using the established diagnostic criteria, i.e. the American Psychiatric Association's classification, Fifth Edition (DSM-V, 2013) and the International Society for Sexual Medicine (ISSM) (Serefoglu et al. 2014) for clinical diagnosis of premature ejaculation (PE).

SA has an experience of diagnosing and treating patients with PE and has been working for 4 years, under the supervision of a Senior Consultant Psychiatrist (HS) who are recognized as a sex therapist by the Medical Privilege and Credentialing Committee, UKMMC. Upon completion of clinical interview, cases ("PE + ve") and non-cases ("PE-ve") of $\mathrm{PE}$, were documented by the researcher (SA), on the back of participants' questionnaire paper. So far, all respondents understood and were comfortable in filling-up the questionnaire. Once completed, the set of questionnaires were returned to the researcher. 


\section{Study Instruments}

\section{A self-constructed questionnaire on demographic details.}

This biodata profile is a brief questionnaire designed to obtain information from the patient, which includes variable such as name, age, educational level, employment status, monthly family income, medical history and frequency of sexual intercourse.

2. The Diagnostic and Statistical Manual's V Edition and ISSM definition criteria for Premature Ejaculation

Premature ejaculation diagnosis was assessed by clinical interview using established diagnostic criteria of the (i) Diagnostic and Statistical Manual's $5^{\text {th }}$ Edition (DSM 5) definition criteria for lifelong PE and (ii) the International Society for Sexual Medicine (ISSM) definition criteria for acquired PE. ${ }^{1,4}$

DSM 5 only gives the definition for lifelong PE (within or less than a minute) and mentioned the lack of data on the time definition for acquired PE. ${ }^{4}$ Hence, it was only until the publication of ISSM's 2014 guidelinethat gave the above time definition for acquire PE of within three minutes of vaginal penetration. ${ }^{1}$

The definition of PE can be conceptualized based on three components. These are (1) time from vaginal penetration to ejaculation (Intravaginal Ejaculation Latency Time or IELT), (2) sense of loss of control over ejaculation and (3) negative personal consequences (distress, bother, avoidance). ${ }^{1}$

\section{International index of Erectile Function 15 (IIEF 15)}

The IIEF 15 was used to presence of erectile dysfunction among the study participants. This is a 15 item self-rating questionnaire, with domains pertaining to Erectile Function (Questions 1,2,3,4,5 \& 15), orgasmic function (Questions $9 \& 10$ ), Sexual Desire (Questions 11

\& 12), Intercourse Satisfaction (Questions 6,7,8), and Overall Satisfaction (Questions 13 \& 14). The original English IIEF 15 was developed by Rosen in $1996,{ }^{16}$ the items are rated on a six grade Likert scale and in reference to the past 4 weeks of sexual activity. ${ }^{12}$ The English version was translated and validated in the Malay language by Quek et al. in a local university hospital population, which had good internal consistency Cronbach's a value of 0.56 and Intraclass correlation, ICC $=0.59 .{ }^{17}$

In this study, study participants were given both versions to choose to fill up. Scoring on the domain of Erectile Function was interpreted as Severe Erectile Dysfunction (1-10), Moderate dysfunction (11-16), Mild to moderate dysfunction (17-21), Mild dysfunction (22-25) and No dysfunction (26-30). ${ }^{18}$ Malay IIEF- 5 has acceptable measurement properties and was recommended for its use in Malaysian clinical practice and research.

\section{Hospital Anxiety and Depression Scale (HADs)}

This instrument was used to assess the presence and severity of both anxiety and depressive symptoms among study participants. It is a 14 item self-rating Likert scale of 0 to 3 . These 14 items comprise of 7 items on anxiety and 7 items on depressive domain. For both domains, a score in the range of 0-7 is considered normal; 8 - 10 as borderline, 11-21 as severe. ${ }^{19}$

A local study by Fatt et al 2007 had validated its use in the Malaysian population and showed good internal consistency and reliability. ${ }^{10}$ This study also demonstrated the ability of HADs to discriminate between premature cases and normal controls. Therefore, the HADs were chosen to be used for this particular research.

The copyright scale both in Malay and English version was obtained from $\mathrm{GL}$ assessment (GL Education Group UK).

\section{RESULTS}

A summary of the baseline characteristics of study participants $(n=120)$ is presented in Table 1 . 
Table 1: Characteristics of participants

\begin{tabular}{|c|c|c|c|c|c|}
\hline \multirow[t]{2}{*}{ Demography } & \multicolumn{2}{|c|}{ Premature Ejaculation } & \multirow[t]{2}{*}{$p$} & \multirow[t]{2}{*}{ OR } & \multirow[t]{2}{*}{$95 \%$ C.I } \\
\hline & Yes $(n=30) 25 \%$ & No $(n=90) 75 \%$ & & & \\
\hline \multicolumn{6}{|l|}{ Age (years) } \\
\hline$\leq 43$ & $12(20.3 \%)$ & $47(79.7 \%)$ & 0.23 & 1.69 & $0.72-3.89$ \\
\hline$\geq 44$ & $18(30.0 \%)$ & $42(70.0 \%)$ & & & \\
\hline \multicolumn{6}{|c|}{ Marital status all were married } \\
\hline \multicolumn{6}{|c|}{ Frequency of sexual intercourse in the last month } \\
\hline None & $6(42.9 \%)$ & $8(57.1 \%)$ & 0.10 & 0.39 & $0.12-1.23$ \\
\hline 1 to 2 times & $11(42.3 \%)$ & 15 (57.7\%) & 0.02 & 0.34 & $0.13-0.87$ \\
\hline 3 to 4 times & $9(26.5 \%)$ & $25(73.5 \%)$ & 0.82 & 0.89 & $0.36-2.23$ \\
\hline 5 to 6 times & $2(10.0 \%)$ & $18(90.0 \%)$ & 0.09 & 3.50 & $0.76-16.1$ \\
\hline 7 to 10 times & $2(11.1 \%)$ & $16(88.9 \%)$ & 0.14 & 3.03 & $0.65-14.0$ \\
\hline$\geq 11$ times & $0(0.0 \%)$ & $8(100.0 \%)$ & 0.09 & 1.36 & $1.22-1.53$ \\
\hline \multicolumn{6}{|l|}{ Race } \\
\hline Malay & $23(23.7 \%)$ & $74(76.3 \%)$ & 0.50 & 0.71 & $0.26-1.94$ \\
\hline Chinese & $1(11.1 \%)$ & $8(88.9 \%)$ & 0.32 & 0.35 & $0.42-2.92$ \\
\hline Indian & $6(50.0 \%)$ & $6(50.0 \%)$ & 0.04 & 3.50 & $1.03-11.8$ \\
\hline Others & $0(0.0 \%)$ & $2(100.0 \%)$ & 0.41 & 0.75 & $0.67-0.83$ \\
\hline \multicolumn{6}{|l|}{ Education level } \\
\hline Primary level & $2(66.7 \%)$ & $1(33.3 \%)$ & 0.09 & 6.35 & $0.56-72.1$ \\
\hline Secondary level & $13(30.2 \%)$ & $30(69.8 \%)$ & 0.32 & 1.53 & $0.66-3.56$ \\
\hline Certificate & $8(19.5 \%)$ & $33(80.5 \%)$ & 0.32 & 0.63 & $2.51-1.57$ \\
\hline Bachelor degree & $5(20.8 \%)$ & 19 (79.2\%) & 0.59 & 0.75 & $0.25-2.21$ \\
\hline Masters/PhD & $2(22.2 \%)$ & 7 (77.8\%) & 0.84 & 0.85 & $0.17-4.32$ \\
\hline \multicolumn{6}{|l|}{ Salary } \\
\hline RM 1,000 -2,000 & $7(36.8 \%)$ & $12(63.2 \%)$ & 0.19 & 1.98 & $0.69-5.61$ \\
\hline RM 3,001- 4,000 & $8(22.9 \%)$ & $27(77.1 \%)$ & 0.73 & 0.85 & $0.34-2.14$ \\
\hline RM 4,001-5,000 & $6(21.4 \%)$ & $22(78.6 \%)$ & 0.62 & 0.77 & $0.28-2.13$ \\
\hline$>$ RM 5,000 & $4(16.7 \%)$ & $20(83.3 \%)$ & 0.29 & 0.54 & $0.17-1.73$ \\
\hline \multicolumn{6}{|l|}{ Employment } \\
\hline Working & $22(22.4 \%)$ & $76(77.6 \%)$ & 0.17 & 0.51 & $0.19-1.36$ \\
\hline Unemployed & $1(50.0 \%)$ & $1(50.0 \%)$ & 0.41 & 3.07 & $0.19-50.64$ \\
\hline Retired & $5(33.3 \%)$ & $10(66.7 \%)$ & 0.43 & 1.61 & $0.50-5.12$ \\
\hline others & $2(50.0 \%)$ & $2(50.0 \%)$ & 0.24 & 3.14 & $0.42-23.35$ \\
\hline \multicolumn{6}{|l|}{ Medical illness } \\
\hline Cholesterol & $0(0.0 \%)$ & $3(100.0 \%)$ & 0.31 & 0.744 & $0.67-0.83$ \\
\hline Prostate disease & $8(44.4 \%)$ & 10 (55.6\%) & 0.04 & 2.91 & $1.03-8.23$ \\
\hline Nephrolithiasis & $2(12.5 \%)$ & $14(87.5 \%)$ & 0.22 & 0.39 & $0.83-1.82$ \\
\hline Thyroid disease & $2(50.0 \%)$ & $2(50.0 \%)$ & 0.24 & 3.14 & $0.42-23.35$ \\
\hline Diabetes & $3(15.8 \%)$ & $16(84.2 \%)$ & 0.31 & 0.51 & $0.32-1.90$ \\
\hline Hypertension & $10(37.0 \%)$ & 17 (63.0\%) & 0.10 & 2.15 & $0.85-5.42$ \\
\hline
\end{tabular}


Subjects were purposively selected from the rology outpatient clinic in a university hospital. 120 subjects who fulfilled the inclusion criteria and completed the questionnaires were included in this study. Most of the participants were in the 31-40 years age category (35\%), followed by $41-50$ years age category $(23.3 \%)$. This sample was not normally distributed with a median age of 43 yearsand standard deviation (SD) of 12.4 years. The majority of participants were Malays (80\%), followed by Indians (10\%), Chinese (7.5\%) and others (2.5\%). The participant's sociodemographic and clinical characteristics are shown in Table 1. Subjects who were clinically diagnosed with PE using DSM 5 \& ISSM definitions was 30 cases out of the 120 participants, giving a prevalence of $25 \%$.

The overall percentage of erectile dysfunction as diagnosed from the IIEF 15 in this study was $56.4 \%$ (mild dysfunction 17.9\%, mild to moderate dysfunction $18.8 \%$, moderate dysfunction $9.4 \%$ and severe dysfunction 10.3\%). Using the Chi-Square analysis, there was a statistically significant difference between erectile dysfunction on the IIEF-15 and PE, $\left(c^{2}=6.732\right.$, df $\left.=1, p=0.01\right)$. A Spearman's rank-order correlation was run to determine the relationship between age and IIEF-15 scores of this sample population. There was a weak, negative correlation between age and
IIEF-15 score, which was statistically significant $\left(r_{s}=-0.224, p=.016\right)$.

In this sample, the majority had normal levels of anxiety $(79.1 \%)$, followed by borderline anxiety levels $(13.91 \%)$ and finally severe levels of anxiety (6.96\%) on the HADS. In the Chi -square analysis, using continuity correction for cells with expected counts less than five, there was a statistically significant difference between severe anxiety levels on HADs and premature ejaculation $\left(c^{2}=6.337\right.$, df $=1, p=0.04$ ).

In the depression subscale of the HADS, only $2.63 \%$ (2) of subjects had severe level of depressive symptoms, whereas $11.40 \%$ had borderline levels of depression and the majority were within normal range (85.96\%). Using a chi-square analysis, there was no association between PE and depression.

\section{Univariate analysis of significant factors associated} with PE

Table 2 shows the significant association factors yielded by this study based on Chi-square analysis. These were frequency of sexual intercourse less than 3 times per month $\left(c^{2}=9.800\right.$, df $=1, p=$ $0.002)$, Indian race $\left(c^{2}=4.444\right.$, $\left.d f=1, p=0.035\right)$, prostate disease $\left(c^{2}=4.270, \mathrm{df}=1, p=0.039\right)$, erectile dysfunction $\left(c^{2}=6.732\right.$, df $\left.=1, p=0.009\right)$ and severe anxiety $\left(c^{2}=6.337, d f=1, p=0.036\right)$.

Table 2. Univariate analysis for significant factors with premature ejaculation

\begin{tabular}{|c|c|c|c|c|c|}
\hline \multirow[t]{2}{*}{ Associated factors } & \multicolumn{2}{|c|}{ Premature ejaculation } & \multirow[t]{2}{*}{ c2 } & \multirow[t]{2}{*}{$p$-value } & \multirow[t]{2}{*}{ OR $(95 \% \mathrm{Cl})$} \\
\hline & $\begin{array}{l}\text { Yes } \\
\mathrm{N}=30 \quad(25 \%)\end{array}$ & \begin{tabular}{|l} 
No \\
$\mathrm{N}=90$ (75\%)
\end{tabular} & & & \\
\hline \multicolumn{6}{|c|}{ Frequency of Sexual intercourse } \\
\hline$\leq 2$ times per month & 17 (42.5\%) & $23(57.5 \%)$ & 9.800 & 0.020 & $0.263(0.111-0.623)$ \\
\hline$\geq 3$ times per month & $13(16.3 \%)$ & $67(83.8 \%)$ & & & \\
\hline \multicolumn{6}{|l|}{ Indian race } \\
\hline Indians & $6(50.0 \%)$ & $6(50.0 \%)$ & 4.444 & 0.035 & $3.500(1.034-11.845)$ \\
\hline Non-Indians & $24(22.2 \%)$ & $84(77.8 \%)$ & & & \\
\hline \multicolumn{6}{|l|}{ Prostate disease } \\
\hline No prostate disease & $22(21.6 \%)$ & $80(78.4 \%)$ & 4.270 & 0.039 & $2.909(1.026-8.252)$ \\
\hline Prostate disease & $8(44.4 \%)$ & $10(55.6 \%)$ & & & \\
\hline \multicolumn{6}{|c|}{ Erectile Dysfunction (IIEF score) } \\
\hline $\begin{array}{l}\text { No ED } \\
\text { (IIEF score 26-30) }\end{array}$ & $44(86.3 \%)$ & $7(13.7 \%)$ & 6.732 & 0.009 & $3.362(1.307-8.647)$ \\
\hline $\begin{array}{l}\text { Mild to severe ED } \\
\text { (IIIEF score 1-25) }\end{array}$ & $43(65.2 \%)$ & $23(34.8 \%)$ & & & \\
\hline \multicolumn{6}{|l|}{ Anxiety (HADs) } \\
\hline $\begin{array}{l}\text { Normal to borderline } \\
\text { (HADs score } 0-10 \text { ) }\end{array}$ & $25(22.3 \%)$ & $87(77.7 \%)$ & 6.337 & 0.036 & $5.800(1.296-25.964)$ \\
\hline $\begin{array}{l}\text { Severe } \\
\text { (HADs score 11-21) }\end{array}$ & $5(62.5 \%)$ & $3(37.5 \%)$ & & & \\
\hline
\end{tabular}

IIEF, International Index of Erectile FunctionED; HADS, Hospital Anxiety and Depression Scale. 


\section{Multivariate analysis}

Logistic regression yielded that the only significant potential risk factors were erectile dysfunction on the IIEF and severe anxiety on the HADS.Men with ED $(p=0.035, O R=3.315,95 \% \mathrm{Cl} 1.088,10.103)$ and anxiety $(p=0.020, O R=7.656,95 \% \mathrm{Cl} 1.383,42.396)$ were more likely to have premature ejaculation.

\section{DISCUSSION}

There has been a renewed interest in PE since the provision of a unified and evidence based definition for PE, which would facilitate clinical research and effective pharmacotherapy options. Epidemiological data on PE in Malaysia has been inadequate and PE's impact on mental health is significant. The prevalence of PE in this study was $25 \%$ using DSM 5 and ISSM definitions. The prevalence rate in this study was comparable with past local studies; Quek et al in 2008 found the prevalence of self-reported $\mathrm{PE}$ in an urban setting was $22.3 \% .{ }^{14}$ In another 2009 study covering Asia Pacific countries. The prevalence of PE among Malaysian men was $29 \% .^{5}$ However, a subsequent study in 2011 found the prevalence of PE was $40.6 \%$ among patients in the primary health care clinic. ${ }^{15}$ This latter's higher prevalence rate could be explained by the sample characteristics, where participants had comorbid medical and psychological health problems. The correlation between sexual health and physical or psychological health has been demonstrated in clinical and epidemiological evidence in a review by Tan HM et al 2012. ${ }^{20}$ Therefore, this could probably reflect such factors in causing higher PE rates.

The prevalence of erectile dysfunction ranging from mild to severe was $56.4 \%$, which was in keeping with the range of reported ED in past studies. ${ }^{21,22}$ The present study also showed that there was an inverse relationship between age and erectile functioning, which is not a surprise as this finding had been replicated in previous local studies by Khoo et al 2008, Tong et al 2011 and Fadzil et al 2014. ${ }^{21,23,24}$ The co-occurrence of ED and PE has been recognized in the literature, with rate as high as $50 \%{ }^{1}$ and the explanation for this relationship has been always in a unidirectional one, in which ED results in $\mathrm{PE}$. Whilst $\mathrm{PE}$ is commonly seen as a psychological condition, ED on the other hand, is commonly associated with vascular-related illnesses, such as hypertension, heart disease, stroke and diabetes. This highlights the need to consider both psychological and organic aspects in patients who presents with a co-occurrence of $\mathrm{PE}$ and ED.
In this study, severe anxiety was found to be associated with presence of PE, and this finding is well established in the literature. ${ }^{1,25,26}$ The relationship between anxiety and PE has been postulated to be a reciprocal one, in which either of these can cause or be the result of one or the other condition. ${ }^{27}$ This could also explain the efficacy of anti-anxiety medications (SSRI), which modulates serotoninergic activity for the treatment for PE. Despite the strong relationship with anxiety, men with $P E$ rarely seek treatment and continue to be impaired both sexually and psychologically. Therefore, the significance of this association is in the clinical management of patients who present with premature ejaculation, should be assessed for presence of anxiety disorder and receive the appropriate treatment.

While multivariate analysis was nonsignificant for infrequent sexual intercourse and prostate disease, these variables were significant in the univariate analysis. The small sample size of this study as indicated by the large confidence interval could explain this negative finding. Previous studies have reported on the association between infrequent sexual intercourse and premature ejaculation ${ }^{12,15,28}$ as well as being postulated as an underlying etiologic basis for premature ejaculation by Kinsey, Pomeroy and Martin. ${ }^{29}$ No significant association was found between PE and age in this study. Although this was consistent with Tang et al 2011, ${ }^{15}$ Quek et al 2008 had demonstrated a decreased prevalence of PE with age. ${ }^{14}$ In an interesting population-based survey in Malaysia ${ }^{30}$ has shown that the prevalence of ED in an Asian population of Malaysia differs from that of the Western population. Lower urinary tract symptoms (LUTS) appeared to correlate with ED, diabetes and obesity, which was not studied in this study.

This study has a number of limitations. The study sample was purposively selected from the urology outpatient clinic with a range of urological and erectile disorders. Therefore, the results of this may not be generalizable to the general population as this study had higher likelihood of detection of premature ejaculation and its association factors. In contrast, it would probably be lesser chance of detecting $P E$ in the general population, given the sensitive nature of disclosing sexual dysfunction in our culture. Hence, a self-report method in the form of a questionnaire would be more appropriate in the general population. Composition of the ethnic group is a limitation to this study as majority of the patients were Malay. Another limitation is the small 
sample size of this study compared to a prevalence study sample size. This would have limited the detection of small effect size and significant differences.

\section{CONCLUSION}

This study has shown the prevalence of PE in urology outpatient males and its significant associated factors for erectile dysfunction and severe anxiety. It is anticipated that using a self-rated instrument to detect PE would have resulted in a higher response rate, given the sensitivity and taboo nature of sexual health issues in Malaysian culture. However, these results cannot be generalized in every Malaysian population, as it is generated in urban Malaysian setting. In conclusion, in a day to day clinical practice, for a routine assessment and treatment for patients with $\mathrm{PE}$, it is paramount to appraise another sexual dysfunction like ED, which may greatly impair their quality of life, and also anxiety that may have negative effect to their sexual performance.

\section{Acknowledgements}

The authors would like to thank Universiti Kebangsaan Malaysia (UKM) Dana-Impak-Perdana fund's DIP No.2014-009 and UKM Medical Faculty FF443-2014 for the grant support.

\section{REFERENCES}

1. Serefoglu EC, MCMahon CG, Waldinger MD, et al. An evidence-based unified definition of lifelong and acquired premature ejaculation: Report of the second international society for sexual medicine Ad Hoc committee for the definition of premature ejaculation. J Sex Med 2014; 11:1423- 41.

2. Porst H, Montorsi F, Rosen RC, et al. The Premature Ejaculation Prevalence and Attitudes (PEPA) Survey: Prevalence, Comorbidities, and Professional Help-Seeking. Eur Urol 2007; 51:816-23.

3. Adaikan PG, Lim P, Ng KK et al. Asian perspective: Premature ejaculation prevalence and attitudes (PEPA) among Singaporean men. Journal of Men's Health 2011; 8 (suppl 1):84-86.

4. American Psychiatric Association. The Diagnostic and Statistical Manual of Mental Disorders, 5th ed. Arlington, VA: American Psychiatric Association, 2013.

5. MCMahon CG, Lee G, Park JK, Adaikan PG. Premature ejaculation and erectile dysfunction prevalence and attitudes in the Asia-Pacific Region. J Sex Med 2012; 9:454-65.

7. Nicolosi A, Glasser DB, Kim SC, et al. Sexual behaviour and dysfunction and help-seeking patterns in adults aged 40-80 years in the urban population of Asian countries. BJU Int 2005;
95:609-614.

8. Sotomayor M. The burden of premature ejaculation: The patient's perspective. J Sex Med 2005; 2(suppl 2):110-4.

9. Rowland DL, Patrick DL, Rothman M, et al. The psychological burden of premature ejaculation. J Urol 2007; 177:1065-70.

10. Rosen RC, Althof S. Impact of premature ejaculation: The psychological, quality of life, and sexual relationship consequence. J Sex Med 2008; 5:1296-307.

11. Fatt QK, Atiya AS, Heng NC, et al. Validation of the Hospital Anxiety and Depression Scale and the psychological disorder among premature ejaculation subjects. Int J Impot Res 2007; 19:321-5.

12. Son $\mathrm{H}$, Song $\mathrm{SH}$, Lee JY, et al. Relationship between premature ejaculation and depression in Korean males. J Sex Med 2011; 8:2062-70.

13. Zhang X, Gao J, Liu J, et al. Distribution and factors associated with four premature ejaculation syndromes in outpatients complaining of ejaculating prematurely. J Sex Med 2013; 10:1603-11.

14. Mourikis I, Antoniou M, Matsouka E, et al. Anxiety and depression among Greek men with primary erectile dysfunction and premature ejaculation. Annals of General Psychiatry 2015; 14:34. doi:10.1186/s12991-015-0074-y.

15. Quek KF, Sallam AA, Ng CH, et al. Prevalence of sexual problems and its association with social, psychological and physical factors among men in a Malaysian population: A cross-sectional study. J Sex Med 2008; 5:70-6.

16. Tang WS, Khoo EM. Prevalence and Correlates of Premature Ejaculation in a Primary Care Setting: A Preliminary Cross-Sectional Study. J Sex Med 2011; 8:2071-8.

17. Rosen RC, Riley A, Wagner G, et al. The international index of erectile function (IIEF): a multidimensional scale for assessment of erectile dysfunction. Urology 1997; 49:822-30.

18. Quek KF, Low WY, Razack AH, et al. Reliability and validity of the Malay version of the International Index of Erectile Function (IIEF-15) in the Malaysian population. Int $\mathrm{J}$ Impot Res 2002; 14:310-5.

19. Cappelleri JC, Rosen RC, Smith MD,et al. Diagnostic evaluation of the erectile function domain of the international index of erectile function. Urology 1999; 54:346-51.

20. Zigmond AS, Snaith RP. The Hospital Anxiety and Depression Scale. Acta Psychiatr Scand 1983; 67:361-70.

21. Tan HM, Tong SF, Ho CC. Men's health: Sexual dysfunction, physical, and psychological healthis there a link? J Sex Med 2012; 9:663-71.

22. Khoo EM, Tan HM, Low WY. Erectile dysfunction and comorbidities in aging men: An urban crosssectional study in Malaysia. J Sex Med 2008; 


\section{5:2925-34}

23. Ho CC, Singam $P$, Hong GE, et al. Male sexual dysfunction in Asia. Asian Journal of Andrology 2011; 13:537-42.

24. Fadzil MA, Sidi $H$, Ismail $Z$, et al. Sociodemographic and psychosocial correlates of erectile dysfunction among hypertensive patients. Compr Psychiatry 2014; (suppl 1):S238.

25. Tong SF, Low WY, Ng CJ. Profile of men's health in Malaysia: Problems and challenges. Asian J Androl 2011; 13:526-33.

26. Dunn KM, Croft PR, Hackett GI. Association of sexual problems with social, psychological, and physical problems in men and women: a cross sectional population survey. J Epidemiol Community Health 1999; 53:144-8.

27. Corona G, Mannucci E, Petrone L, et al. Psychobiological correlates of free-floating anxiety symptoms in male patients with sexual dysfunctions. J Androl 2006; 27:86-93.

28. Rajkumar RP, Kumaran AK. The association of anxiety with the subtypes of premature ejaculation: A Chart Review. Prim Care Companion CNS Disord 2014; 16.

29. MCMahon CG. Premature ejaculation. Indian Journal of Urology: IJU: Journal of the Urological Society of India 2007; 23:97-108.

30. Bullough VL, Bullough B. Human Sexuality: An Encyclopedia. Garland Publishing Inc, 2014.

31. Mariappan P and Chong WL. Prevalence and correlations of lower urinary tract symptoms, erectile dysfunction and incontinence in men from a multiethnic Asian population: results of a regional population-based survey and comparison with industrialized nations. BJU 2006; 98: 1264 - 69. 